\title{
Student characteristics associated with dominant approaches to studying: Comparing a national and an international sample
}

Mikkel M. Thørrisen ${ }^{1,2 *}$

Gry Mørk ${ }^{3}$

Lene Angell Åsli ${ }^{4}$

Astrid Gramstad ${ }^{4,5}$

Linda Stigen ${ }^{6}$

Trine A. Magne ${ }^{7}$

Tove Carstensen ${ }^{7}$

Susanne Grødem Johnson ${ }^{8}$

Ted Brown ${ }^{9}$

Hua Beng Lim $^{10}$

Kenneth N. K. Fong ${ }^{11}$

Tore Bonsaksen ${ }^{1,3,12}$

${ }^{1}$ Department of Occupational Therapy, Prosthetics and Orthotics, Faculty of Health Sciences, OsloMet - Oslo Metropolitan University, Oslo, Norway

${ }^{2}$ Department of Public Health, Faculty of Health Sciences, University of Stavanger, Stavanger, Norway

${ }^{3}$ Faculty of Health Studies, VID Specialized University, Sandnes, Norway

${ }^{4}$ Department of Health and Care Sciences, Faculty of Health Sciences, UiT - The Arctic University of Norway, Troms $\varnothing$, Norway

${ }^{5}$ Centre for Care Research, North, Troms $\varnothing$, Norway

${ }^{6}$ Department of Health Sciences, Faculty of Medicine and Health Sciences, Norwegian University of Science and Technology (NTNU), Gjøvik, Norway

${ }^{7}$ Department of Neuromedicine and Movement Science, Faculty of Medicine and Health Sciences, Norwegian University of Science and Technology (NTNU), Trondheim, Norway

${ }^{8}$ Department of Health and Function, Western Norway University of Applied Sciences, Bergen, Norway

${ }^{9}$ Department of Occupational Therapy, School of Primary and Allied Health Care, Faculty of Medicine, Nursing and Health Sciences, Monash University - Peninsula Campus, Frankston, Victoria, Australia

${ }^{10}$ Health and Social Sciences Cluster, Singapore Institute of Technology, Singapore

${ }^{11}$ Department of Rehabilitation Sciences, Hong Kong Polytechnic University, Hong Kong

${ }^{12}$ Department of Health and Nursing Sciences, Faculty of Social and Health Sciences, Inland Norway University of Applied Sciences, Elverum, Norway 
1 *Corresponding author: Mikkel M. Thørrisen, Department of Occupational Therapy,

2 Prosthetics and Orthotics, Faculty of Health Sciences, OsloMet - Oslo Metropolitan

3 University, Oslo, Norway. mikkel-magnus.thorrisen@ oslomet.no

4

5

\section{Abstract}

Background: Productive approaches to studying (deep and strategic learning) are associated with a variety of favorable academic outcomes, and may be of particular importance for students in multifaceted and complex disciplines such as occupational therapy. Aim: To explore associations between student characteristics and their dominant approaches to studying in two samples of occupational therapy students: A national sample of Norwegian first-year students, and an international sample of students in different year cohorts (Australia, Hong Kong, Singapore and Norway). Materials and methods: 180 (national sample) and 665 (international sample) students were included in the study. Approaches to studying were measured with the Approaches to Study Skills Inventory for Students (ASSIST). Data were analyzed with adjusted multinomial regression analyses. Results: Age, gender and prior higher education were not associated with dominant study approach. More time spent on independent study (international sample: $\mathrm{OR}=1.07 / 1.08, p<.01 /<.001$ ) and having current study program as the top priority line of education at enrolment (national sample: $\mathrm{OR}=2.89$, $p<.05)$ predicted productive study approaches. Conclusions and significance: Factors such as age, gender and prior higher education seem to be of limited importance for understanding students' dominant approaches to studying.

Keywords: Higher education; learning; multinomial logistic regression; occupational therapy 


\section{Introduction}

Students differ in how they approach their studies. 'Approach to study' refers to how students orient themselves towards learning in academic situations [1]. A student's approach to study is developed through interactions between individual characteristics and factors related to the learning environment. An approach to study is more complex than a specific type of learning style, insofar that the latter primarily refers to individual dispositions that are stable in nature [2]. In their influential theoretical framework, Entwistle and Ramsden [3] distinguished between three approaches to study: (i) a surface approach that is characterized by investing the least possible effort in order to pass necessary exams, with an emphasis on passive information processing and reproduction of memorized knowledge [2-4], (ii) a deep approach that comprises processes of examining, connecting and integrating ideas and knowledge in order to construct personal meaning from the study materials [2,5], and (iii) a strategic approach that encompasses elements of both deep and surface studying, characterized by a flexible, organized and achievement-oriented adaptation of study efforts in accordance with external academic demands [6].

A deep approach to studying has, quite consistently, been associated with higher academic achievements, as demonstrated in heterogeneous student samples [7,8], as well as in discipline-specific samples, such as medical students [9,10], chemistry students [11], and occupational therapy students [12]. A deep study approach has been associated with a variety of other favorable outcomes, e.g., lower self-handicapping (less public expression of external explanations/excuses for anticipated failures) [7,13], higher student reflectivity [7], and more time spent on independent study tasks [14]. Similarly, higher academic achievements have been associated with a strategic study approach $[12,15]$. Conversely, a surface approach to studying has been linked to several detrimental outcomes, such as lower academic achievement [12,15-19], increased risk of dropping out of academic study programs [20], 
1 lower academic expectations [7], increased test anxiety [21], and higher levels of stress [22].

2 Deep and strategic approaches to studying may thus be characterized as productive approaches [23] that ought to be encouraged and promoted by educational institutions. In the

following, we will therefore use this term to denote deep and strategic approaches to studying. Studies have demonstrated that factors related to the learning environment may influence students' approach to studying, such as workload [4,24], teaching methods [4,25,26], teacher approach [27,28], and assessment and feedback procedures [4,29,30]. Some studies have suggested that students embrace more productive approaches to studying as their study experience increases $[16,31,32]$, while others have proposed the opposite, i.e., a gradual shift from deeper to more surface orientations [33,34].

Studies exploring individual motivational factors imply that a deep approach to studying is predicted by a high degree of identification with one's field of study [35] and an intrinsic study motivation $[27,36]$. Moreover, a deep orientation has been associated with high levels of self-confidence, self-efficacy, organizational skills, time management abilities, dedication and self-regulation [27,36-38], as well as certain personality traits [27]. A preference for teaching where educators emphasize understanding, rather than information transfer, has been linked to productive approaches to study and academic engagement $[27,39]$.

Several studies have explored the importance of students' demographic factors for understanding study approaches, yet investigations have often yielded inconclusive and/or conflicting results $[27,40]$. Some studies have found that males are more prone than females to surface studying $[41,42]$, while others have found the opposite $[28,39,43]$. Likewise, studies have reported conflicting results regarding the association between gender and productive approaches to study $[18,41,43,44]$. Interestingly, several other studies have documented no significant differences between genders [17,34,45-48]. Across countries and study disciplines, research has generally found that higher student age is associated with an 
1

inclination to adopt a deep or strategic study approach [37,39,45,46,48]. However, several studies have not been able to demonstrate a significant relationship between age and approach to academic studies $[34,42,47,49]$.

As study approaches are generally assumed to influence academic performance, more knowledge about factors associated with their use may elicit a better understanding of students undergoing occupational therapy education. Further, as previous studies of occupational therapy students have focused on factors associated with each of the study approaches [37,39], studies examining a set of variables in relation to the three study approaches as concurrent outcomes may elaborate on the insights derived from previous studies. One may argue that strategic and deep study approaches are particularly important for students in multifaceted and complex fields such as occupational therapy. The occupational therapy process involves identifying client concerns, needs and goals, evaluating occupational performance limitations and assets, and designing, implementing and evaluating interventions [50]. Moreover, the occupational therapy student must learn to understand and apply theoretical knowledge [51], and integrate this knowledge base with personal and professional experience [52]. More knowledge about the factors of importance for successful studying may translate into a positive development for the future of professional practice.

A thorough understanding of students' approaches to studying requires exploration of both modifiable and non-modifiable factors. Knowledge about modifiable factors may be directive in determining which components should be targeted by interventions, while knowledge on non-modifiable factors may contribute to a better understanding of what characterizes individuals and subgroups who may particularly benefit from such interventions. By exploring associations between student characteristics and dominant approaches to studying, the current study focused primarily on the latter. Student variables such as gender, age and higher education experience are not amenable to intervention. Still, knowledge about such 
associations may enable institutions to identify students that may particularly benefit from interventions aimed at encouraging productive approaches to academic study. Current research evidence on students' demographic factors and associations with study approaches stands out as inconclusive and conflicting. Moreover, research on such relationships among occupational therapy students is sparse. Research has demonstrated associations between factors residing in the learning environment and students' approaches to studying. However, learning environments may vary across institutions and cultures, and dominant study approaches may vary between diciplines. Hence, studying the relative importance of student characteristics within a single institution, within a single culture or across different disciplines is somewhat challenging. This study adds to existing literature by examining the importance of student characteristics among students from the same discipline across institutions and cultures, i.e., by investigating whether patterns of associations between student characteristics and study approaches were similar in different educational and cultural contexts.

\section{Study aim}

The aim of this study was (i) to explore associations between student characteristics and dominant approaches to studying, and (ii) to compare whether these patterns of associations were similar in different educational and cultural contexts, by comparing results from a national sample of Norwegian first-year undergraduate occupational therapy students and an international sample of undergraduate occupational therapy students from Australia, Hong Kong, Singapore and Norway in different year level cohorts.

\section{Methods}

\section{Design and study context}


1 The research reported in this paper is part of the international Learning Environment and

2 Approaches to Studying among Occupational Therapy Students project. The study was crosssectional and based on data collected from two samples: (i) a national sample of first-year undergraduate occupational therapy students in Norway, collected in 2017/2018 and (ii) an international sample of undergraduate occupational therapy students from four different year level cohorts in Australia, Hong Kong, Singapore and Norway, gathered in 2014.

\section{Recruitment and response rate}

For the national sample, students enrolled in the first year at each of the six occupational therapy undergraduate education programs in Norway were invited to participate. Threehundred-and-five students were eligible to take part, and 187 (response rate $=61.3 \%$ ) chose to participate. Of these recruited students, 180 had valid scores on all variables employed in the analyses. Faculty members at each education program distributed the questionnaires and consent forms to the students.

For the international sample, the questionnaires were completed by 712 students, representing $66.1 \%$ of the total number of students at four sites. Response rates for Australia were $n=376 / 410(91.7 \%)$, for Hong Kong $n=109 / 355(30.7 \%)$, for Norway $n=160 / 245$ $(65.3 \%)$, and for Singapore $n=67 / 67$ (100\%). Participants from Australia were from all four study years (first year $n=170$; second year $n=77$; third year $n=73$; and fourth year $n=56$ ). The Norwegian participants were from all three year levels (first year $n=57$; second year $n=$ 50; and third year $n=53$ ). Participants from Hong Kong were predominantly in the first and third study years (first year $n=37$; second year $n=5$; and third year $n=23$ from the 4-year program; and third year $n=44$ from the 3-year program). Lastly, only first year students were included in Singapore $(n=67)$. Of the 712 recruited students, 665 had valid scores on the 
1

variables employed in the analyses. Faculty members at each education program distributed the questionnaires and consent forms to students.

\section{Measurements}

Demographic and education-related characteristics. Information about age, gender and education (prior higher education versus no prior higher education, and hours spent engaging in independent study during a typical week) was collected. Age was categorized as $\leq 19$ years, 20-24 years, 25-29 years, 30-35 years, 36-39 years, and $\geq 40$ years. In the national sample, the participants also provided information on whether occupational therapy was their priority line of study at the time of enrollment (yes/no).

Approaches to studying. Data related to the students' approaches to studying were obtained from the 52-item Approaches and Study Skills Inventory for Students (ASSIST [6]). For the Norwegian students in both samples, a previously validated Norwegian version of the ASSIST was used [53]. As established from prior psychometric studies, the ASSIST items are organized into three main factors, namely the deep, strategic, and surface approaches [54-56]. The three approaches to study are composed of several subscales, each of which contain four items. The deep approach consists of four subscales (seeking meaning, relating ideas, use of evidence, and interest in ideas); the strategic approach consists of five subscales (organized study, time management, alertness to assessment demands, achieving, and monitoring effectiveness); and lastly, the surface approach consists of four subscales (lack of purpose, unrelated memorizing, syllabus-bound, and fear of failure). Respondents were asked to report their level of agreement with items such as “when I'm reading an article or a book, I try to find out for myself exactly what the author means" (deep approach), "I work steadily through the term or semester, rather than leave it all until the last minute" (strategic approach), and 
1 "much of what I'm studying makes little sense: it's like unrelated bits and pieces" (surface approach). Each ASSIST item is scored on a Likert scale ranging from 1 (disagree) to 5 (agree). Completing the ASSIST takes approximately 10-15 minutes.

The original English language version of the ASSIST have demonstrated satisfactory internal consistency for the main scales (Cronbach's $\alpha$ ranging $0.61-0.88$ ) when used with students in different academic and professional areas [54,56-59]. The Norwegian language version of the ASSIST has been examined using factor analytic procedures [60] and structural equation modelling [53], and yielded the same three latent factors (deep, strategic, and surface approaches). In the national sample, internal consistency estimates (Cronbach's $\alpha$ ) for the study approach scales were 0.71 (deep approach), 0.84 (strategic approach), and 0.76 (surface approach). In the international sample, internal consistency was 0.79 (deep approach), 0.84 (strategic approach), and 0.74 (surface approach).

\section{Data analysis}

All analyses were performed separately on the national and international sample. All data were entered into IBM SPSS version 26 [61]. Descriptive analyses were performed on all variables using means $(M)$, standard deviations $(S D)$, frequencies and percentages as appropriate. Scores on the deep-, strategic-, and surface scales were normalized; i.e., divided by the number of items belonging to each scale. The resulting scale scores ranged from 1 to 5 . Based on their highest normalized scale score, all students were categorized as either deep, strategic or surface learners, thus three groups of students were constituted. Overall differences between the three groups were investigated with Chi-square tests for categorical variables and with one-way analysis of variance (ANOVA) for continuous variables.

Subsequently, multinomial logistic regression analyses were used to examine the adjusted associations between demographic and education-related characteristics (age group, gender, 
1 prior higher education experience, and time spent engaging in independent study during a

2 typical week) and dominant study approach (deep versus strategic versus surface approach) as

3 the outcome variable. In analyses of the national sample, having or not having occupational

4 therapy as the highest priority line of study at enrollment was used as an additional

5 independent variable. The surface approach was used as the reference category.

6 Statistical significance was set at $p<0.05$. For each main analysis, reaching the minimum

7 required sample size was defined as fulfilling two criteria: (i) the sample size had to exceed a

8 ratio of 15 participants per independent variable [62], and (ii) the sample size had to exceed a

9 number of participants according to the formula $N>50+(8 \times$ number of independent

10 variables) [63].

\section{Ethics}

For the national sample, approval for collecting and storing the data was granted by the Norwegian Center for Research Data (NSD). For the international sample, ethical approval and approval for collecting and storing data was granted by the following ethics review boards/data protection agencies: Monash University Human Research Ethics Committee (MUHREC; for Monash University); the Norwegian Center for Research Data (NSD; for Oslo Metropolitan University); the Human Subject Ethics Application Review System (HSEARS; for Hong Kong Polytechnic University); and Nanyang Polytechnic, School of Health Sciences Projects Review Committee (for Nanyang Polytechnic). In both samples, the students were informed that completion of the questionnaire was voluntary, that their responses would be treated in confidence, and that there would be no negative consequences from opting not to participate in the study. Written informed consent was provided from all participants. 


\section{Results}

\section{National sample}

3 Participants. The demographic and education-related characteristics of the participants in the national sample, and their scores on the study approach scales, are reported in Table 1 according to the dominant study approaches. The unadjusted analysis revealed unequal gender proportions classified with the three dominant study approaches $(p<0.01)$. Among the male students, the largest proportion was classified as deep learners $(61.1 \%)$, while the largest proportion of female students were classified as strategic learners (55.6\%). Relatively small proportions were classified as surface learners $(8.3 \%$ of male students and $14.6 \%$ of female students, respectively). The normalized mean scores on the three study approach scales followed the expected pattern: The mean deep approach score was highest among students classified as deep learners, the mean strategic approach score was highest among students classified as strategic learners, and the mean surface approach score was highest among students classified as surface learners (all $p<0.001$ ).

\section{INSERT TABLE 1 ABOUT HERE}

\section{Associations between student characteristics and dominant study approach. In the} adjusted multinomial regression analyses (Table 2), none of the independent variables significantly predicted the deep approach to study as the dominant approach, compared to the surface approach to study. However, we noted a non-significant association between male gender and higher odds of being classified as a deep learner, compared to a surface learner $(\mathrm{OR}=3.23, p=0.09)$. Students who reported having had occupational therapy as their top priority line of education at the time of enrollment had increased odds for having a dominant strategic approach to studying, compared to a surface approach $(\mathrm{OR}=2.89, p<0.05)$. 


\section{INSERT TABLE 2 ABOUT HERE}

\section{International sample}

Participants. The demographic and education-relation characteristics of the participants in the international sample, and their scores on the study approach scales, are displayed in Table 3 according to their dominant study approaches. The unadjusted analyses revealed unequal gender proportions between the dominant study approaches $(p<0.05)$. Among the male students, the proportions classified as deep learners (46.2\%) and strategic learners (43.0\%) were relatively similar in size, while the largest proportion of female students were classified as strategic learners (54.2\%). Surface learners were relatively few (10.8\% among male students and $13.3 \%$ among female students, respectively). The number of hours spent engaging in independent study during a typical week was also different between the groups, with more hours spent among deep learners $(M=12.6$ hours, $S D=7.7$ hours $)$ and strategic learners $(M=13.8$ hours, $S D=9.0$ hours $)$, while fewer hours were spent among the surface learners $(M=10.0$ hours, $S D=6.2$ hours, $p<0.01)$.

The normalized mean scores on the three study approach scales followed the expected pattern: the mean deep approach score was highest among students classified as deep learners, the mean strategic approach was highest among students classified as strategic learners, and the mean surface approach score was highest among students classified as surface learners (all $p<0.001)$. 
1 Associations between student characteristics and dominant study approach. In the

2 adjusted multinomial regression analyses (Table 4), spending more hours on independent

3 studying during a typical week significantly predicted a dominant deep approach to study,

4 compared to the surface approach $(\mathrm{OR}=1.07, p<0.01)$. In addition, a borderline significant

5 association was noted between male gender and higher odds of being classified as a deep

6 learner, compared to a surface learner $(\mathrm{OR}=2.11, p=0.05)$. Students who reported spending more time involved in independent study during a typical week also had increased odds for a dominant strategic approach to studying, compared to a surface approach $(\mathrm{OR}=1.08, p<$ $0.001)$.

INSERT TABLE 4 ABOUT HERE

This study explored associations between occupational therapy students' background characteristics and their dominant approaches to studying, based on two samples: a national sample of Norwegian first-year students, and an international sample of students in different year cohorts. Our main findings were the following: First, age, gender and prior higher education experience were not associated with students' dominant approach to study. Second, more time spent on independent study predicted productive study approaches (deep and strategic) in the international sample, but not in the national sample. Third, having the current study program (occupational therapy) as the top priority line of education at the time of enrollment predicted a strategic approach in the national sample. It should be noted that this was not measured in the international sample.

The pattern of study approach distributions was similar across the two samples. Overall, strategic learners were most prevalent, followed by deep and surface learners. Among males, 
1 the deep approach was somewhat overrepresented, while the strategic approach was most

2 common among females. This pattern is consistent with findings from heterogeneous student samples in Turkey and Taiwan (males higher on deep learning) [41], and among math students in Vietnam (females higher on strategic learning) [18]. However, we were not able to demonstrate significant associations between gender and students' approach to study, in line with previously reported studies involving psychology students $[45,46]$, medical students $[17,47]$ and science students [48]. In general, it is complicated to explain phenomena that are formed and developed on the basis of interactions between and combinations of inherent and acquired factors. This may be the case with students' approaches to study, which is formed and developed through interactions between individual characteristics and environmental factors. According to Richardson and King [64], it is difficult to identify reliable gender differences when the relationship between gender and study approach is investigated directly, since gender differences may be contingent upon the study discipline and learning environment [65]. Perhaps to some degree comparable, studies of personality - a phenomenon that is formed by both nature and nurture [66] - have often concluded that gender differences are small, relative to individual variations within genders [67].

Moreover, this study does not provide support for previous research that have found that higher age tend to be associated with application of more productive study approaches $[37,39,45,46,48]$. It has been proposed that the association between higher age and productive study approaches is reflected by level of maturity [68], and that this may be due to mature students having more life experience and being more motivated by intrinsic goals [69]. However, we did not find a significant relationship between age and students' approach to study, which is in line with other inconclusive studies [34,42,47,49]. Moreover, we did not find a significant association between prior higher education experience and dominant study approach. Few studies have explicitly explored the role of prior higher education experience, 
which may reflect students' level of study maturity. A notable exception is a study among Norwegian occupational therapy students [37] that revealed that students without prior higher education were more prone to adopt a surface approach to studying. However, studies exploring temporal changes in preferred approaches to study throughout the course of an education program have yielded inconclusive results [16,31-34]. For instance, Bonsaksen et al. [32] demonstrated a decrease in surface approach between first and third-year occupational therapy students, while Shah et al. [34] reported a gradual shift from deeper to more surface learning among health sciences students. Our results question the importance of maturity in understanding students' approaches to study, although it should be noted that the age distributions in our samples were quite narrow, with the majority of students being aged between 20 and 24 years (national sample: $71.7 \%$; international sample: $57.6 \%$ ).

In the international sample, it was found that students who spent more time engaging in independent study were more inclined to adopt productive study approaches. This finding among occupational therapy students is thus comparable to Entwistle and Tait's [14] study of engineering students that concluded that more time spent on independent study was associated with embracing a meaningful orientation to learning. Time spent engaging in independent study may be interpreted as a reflection of students' interest in, dedication and motivation for the course, and may thus reflect an intrinsic motivation towards study, which in previous studies has been linked to productive study approaches $[27,35,36]$. The findings from the current study do not explain why significant associations between involvement in independent study and approaches to study were not found in the national student sample. It may be due to actual differences in higher education study programs and learning environments, as a result of the national sample (composed of just first-year students) having less experience with their line of study than the international sample (that involved students across all year levels), or 
1 perhaps as a consequence of lower statistical power (lower sample size) in the national

2 sample.

3 In the national sample of students, having occupational therapy as the top priority rank of

4 educational choice of program at enrollment predicted the adoption of a strategic (compared

5 to a surface) approach to study. It is plausible to assume that students granted their top study

6 priority choice are more intrinsically motivated for studying than students who are refused their top priority and instead granted occupational therapy studies as an alternate choice. This may partially explain why students who were granted their top ranked study area of choice were characterized by an increased strategic learning strategy. Study choice ranking (i.e., priority) at initial enrollment into the occupational therapy course was not measured in the international sample.

\section{Educational implications}

Taken together, the results from both the national and international samples of undergraduate occupational therapy students suggest that student factors such as gender, age and prior higher education experience are of less importance when attempting to understand students' approaches to studying, while factors that may relate more to students' motivation (time spent engaging in independent study in the international sample; having occupational therapy as the top ranked choice of university academic course in the national sample) seem to be more important. As such, this study does not provide support for educational institutions to target specific student groups based on factors such as gender, age and prior education experience. On the other hand, our results indicate that teachers should stimulate students' independent studying, and that institutions should have a particular awareness of students whom at enrollment did not have occupational therapy as their priority line of education. 


\section{$1 \quad$ Methodological issues}

2 The present study has several strengths. The results are based on data from both a national and an international sample (four countries) of students within the same study discipline across study year cohorts. The response rates were quite high (national sample $=61.3 \%$; international sample $=66.1 \%$ ), and the sample sizes were statistically satisfactory by well exceeding a recommended ratio of 15 participants per independent variable (national sample:

$\frac{180 \text { participants }}{5 \text { predictors }}=36$ participants per predictor; international sample: $\frac{665 \text { participants }}{4 \text { predictors }}=166.25$ participants per predictor) [62], and by exceeding a required sample size in concordance with the formula $N>50+(8 \times$ number of independent variables) [63]. However, in the international sample, the number of students was not evenly distributed between the four countries. This was due to the eligible subsamples varying in size and response rates. Consequently, subsamples from large institutions and institutions with high response rates were ascribed undue weight, which may somewhat have biased the results. Within the scope of this study, we were not able to explore and address specific cultural differences between the countries from which the study populations were drawn.

Utilizing an international sample consisting of students from only Australia, Norway, Hong Kong and Singapore may constitute a limitation. However, previous studies have explored and compared occupational therapy students from these countries [70,71], and psychometric properties of the ASSIST instrument have been investigated in a similar international sample [60], revealing that the instrument structure was quite satisfactory across the four country cohorts. The current study did not aspire to provide representative comparisons, but the study aim was to explore the relative importance of student characteristics in a somewhat wider context than simply studying students from a single institution or a single culture. Future research could benefit from including more 
1

2

representative cross-cultural student samples and differentiating between students at different year levels.

The outcome variables (study approaches) were measured with the Approaches to Study Skills Inventory for Students (ASSIST [6]), an instrument that has demonstrated satisfactory measurement properties across languages as well as across academic and professional areas [53,54,56-60]. The cross-sectional design of this study does, however, pose certain limitations. By studying cross-sectional relationships between predictors and outcomes, we were able to explore associations, yet unable to draw causal inferences. For instance, we identified a significant association between time spent on independent studying and study approaches. It may well be that considerable independent studying leads to a productive study approach. However, the opposite may also be true, i.e., that a productive study approach leads to more independent studying, or that some extraneous factor(s) (e.g., motivation) were the cause of both. Future research would benefit from exploring study approaches by means of more robust research designs, such as controlled prospective cohort studies or retrospective case-control studies. Potential effects of student characteristics on study approach may be mediated and moderated by a wide range of variables not measured in this study. Moreover, potential effects of a wide range of variables may be mediated or moderated by student characteristics. A more comprehensive understanding of the relationship between student characteristics and approaches to study seems to hinge on the exploration of complex mechanisms of mediation and moderation, as well as on more secondary research efforts (systematic reviews, preferably with meta-analyses).

Productive approaches to studying (deep and strategic learning) are associated with a variety of favorable academic outcomes. Knowledge of factors that enhance productive approaches 
1

2

3

4

(3)

5

may enable educational institutions to encourage deep and strategic study approaches among

students. Factors such as age, gender and prior higher education seem to be of limited importance for understanding students' study approaches. Taking previous findings into consideration, factors relating to the learning environment and students' motivation stand out as more pivotal.

\section{Declarations}

\section{Conflicts of interest}

The authors declare that they have no conflicts of interest.

\section{Data availability}

The data used to support the findings of this study are available from the corresponding author upon reasonable request.

\section{Funding}

The study received no funding.

\section{Acknowledgements}

The authors would like to thank the students who volunteered to take part in this study. In addition we thank Vår Mathisen (UiT - The Arctic University of Norway, Troms $\varnothing$ ) and Kjersti Velde Helgøy (VID Specialized University, Sandnes), who contributed to the data collection for this study.

3

4




\section{References}

1. Richardson JTE. Approaches to studying across the adult life span: Evidence from distance education. Learn Individ Differ. 2013;26:74-80.

2. Biggs J, Tang C. Teaching for quality learning at university. Maidenhead (UK): McGrawHill Education; 2007.

3. Entwistle N, Ramsden P. Understanding student learning. London (UK): Croom Helm; 1983.

4. Dolmans DH, Loyens SM, Marcq H, Gijbels D. Deep and surface learning in problembased learning: A review of the literature. Adv Health Sci Educ. 2016;21:1087-112.

5. Entwistle N, Walker P. Conceptions, styles, and approaches within higher education: Analytic abstractions and everyday experience. In: Sternberg RJ, Zhang L, editors. Perspectives on thinking, learning, and cognitive styles. Mahwah (NJ): Taylor \& Francis; 2001. p. 103-36.

6. Tait H, Entwistle N, McCune V. ASSIST: A reconceptualisation of the Approaches to Studying Inventory. In: Rust C, editor. Improving student learning: Improving students as learners. Oxford (UK): Oxford Center for Staff and Learning; 1998. p. 262-71.

7. Cano F, Martin AJ, Ginns P, Berben ABG. Students' self-worth protection and approaches to learning in higher education: predictors and consequences. High Educ. 2018;76:163-81.

8. Herrmann KJ, Bager-Elsborg A, McCune V. Investigating the relationships between approaches to learning, learner identities and academic achievement in higher education. High Educ. 2017;74:385-400.

9. Shaik SA, Almarzuqi A, Almogheer R, Alharbi O, Jalal A, Alorainy M. Assessing Saudi medical students learning approach using the revised two-factor study process questionnaire. Int J Med Educ. 2017;8:292-6.

10. Paudel KR, Nepal HP, Shrestha B, Panta R, Toth S. Distribution and academic significance of learning approaches among pre-clinical medical students at Trinity School of Medicine, St Vincent and the Grenadines. J Educ Eval Health Prof. 2018;15.

DOI:10.3352/jeehp.2018.15.9

11. Ninkovic SO, Adamov J, Jesic LV. Relation between learning approaches of chemistry students and their achievement in general chemistry. Maced J Chem En. 2019;38:293.

12. Bonsaksen T, Brown T, Lim HB, Fong K. Approaches to studying predict academic performance in undergraduate occupational therapy students: a cross-sectional study. BMC Med Educ. 2017;17. DOI:10.1186/s12909-017-0914-3

13. Berglas S. The self-handicapping model of alcohol abuse. In: Blane HT, leonard KE, editors. Psychological theories of drinking and alcoholism. New York (NY): Guilford; 1987. p. $305-45$. 
14. Entwistle N, Tait H. Approaches to learning, evaluations of teaching, and preferences for contrasting academic environments. High Educ. 1990;19:169-94.

15. Chen BH, Chiu WC, Wang CC. The relationship among academic self-concept, learning strategies, and academic achievement: A case study of national vocational college students in Taiwan via SEM. Asia-Pac Educ Res. 2015;24:419-31.

16. Bickerdike A, O'Deasmhunaigh C, O'Flynn S, O'Tuathaigh C. Learning strategies, study habits and social networking activity of undergraduate medical students. Int J Med Educ. 2016;7:230-6.

17. Kamath A, Rao R, Shenoy PJ, Ullal SD. Approaches to learning and academic performance in pharmacology among second-year undergraduate medical students. Sci Med. 2018;28. DOI:10.15448/1980-6108.2018.4.32395

18. Nguyen TM. Learning approaches, demographic factors to predict academic outcomes. Int J Educ Manag. 2016;30:653-67.

19. Takase M, Imai T, Niitani M, Okada M. Teaching context contributing to nursing students' adoption of a deep approach to learning. J Prof Nurs. 2019;35:379-88.

20. Lastusaari M, Laakkonen E, Murtonen M. Persistence in studies in relation to learning approaches and first-year grades: A study of university chemistry students in Finland. Chem Educ Res Pract. 2019;20:452-67.

21. Cipra C, Muller-Hilke B. Testing anxiety in undergraduate medical students and its correlation with different learning approaches. PLoS ONE. 2019;14.

DOI:10.1371/journal.pone.0210130

22. Öhrstedt M, Lindfors P. Linkages between approaches to learning, perceived stress and expected and actual academic outcomes among first-semester psychology students. J Furth High Educ. 2018;42:116-29.

23. DaLomba E, Stigen L, Johnson SG, Mørk G, Gramstad A, Magne TA, et al. Psychometric properties and associations between subscales of a study approach measure. Nurs Health Sci. 2020. DOI:10.1111/nhs. 12750

24. Ullah R, Richardson JTE, Malik RA, Farooq S. Perceptions of the learning environment, learning preferences, and approaches to studying among medical students in Pakistan. Stud Educ Eval. 2016;50:62-70.

25. Alquliti A, abd Elmoneim E, Albouq N, Aboonq M, Jalali K, Arabi S, et al. Students' approaches to learning and perception of learning environments: A comparison between traditional and problem based learning medical curricula. Egypt J Hosp Med. 2019;74:124250 .

26. Wang JS, Pascarella ET, Laird TFN, Ribera AK. How clear and organized classroom instruction and deep approaches to learning affect growth in critical thinking and need for cognition. Stud High Educ. 2015;40:1786-807. 
27. Baeten M, Kyndt E, Struyven K, Dochy F. Using student-centered learning environments to stimulate deep approaches to learning: Factors encouraging or discouraging their effectiveness. Educ Res Rev. 2010;5:243-60.

28. Duff A, McKinstry S. Students' approches to learning. Issues Account Educ. 2007;22:183-214.

29. Aaron S, Skakun E. Correlation of students' characteristics with their learning styles as they begin medical school. Acad Med. 1999;74:260.

30. Ramsden P. Learning to teach in higher education. 2nd ed. London (UK): Falmer Press; 2003.

31. Chung EK, Elliott D, Fisher D, May W. A comparison of medical students' learning approaches between the first and fourth years. South Med J. 2015;108:207-10.

32. Bonsaksen T, Thørrisen MM, Sadeghi T. Occupational therapy students in Norway: Do their approaches to studying vary by year in the program? The Open Journal of Occupational Therapy. 2017;5. DOI:10.15453/2168-6408.1339

33. Barac K, Kirstein M, Kunz R, Beukes B. Factors influencing students' learning approaches in auditing. Meditari Account Res. 2016;24:390-413.

34. Shah DK, Yadav RL, Sharma D, Yadav PK, Islam N, Sapotka NK, et al. Learning approach among health sciences students in a medical college in Nepal: a cross-sectional study. Adv Med Educ Pract. 2016. DOI:10.2147/amep.s100968

35. Smyth L, Mavor KI, Platow MJ, Grace DM, Reynolds KJ. Discipline social identification, study norms and learning approach in university students. Educ Psychol. 2015;35:53-72.

36. Prat-Sala M, Redford P. The interplay between motivation, self-efficacy, and approaches to studying. Brit J Educ Psychol. 2010;80:283-305.

37. Bonsaksen T, Sadeghi T, Thørrisen MM. Associations between self-esteem, general self-efficacy, and approaches to studying in occupational therapy students: A cross-sectional study. Occupational Therapy in Mental Health. 2017;33:326-41.

38. Heikkilä A, Niemivirta M, Nieminen J, Lonka K. Interrelations among university students' approaches to learning, regulation of learning, and cognitive and attributional strategies: a person oriented approach. High Educ. 2011;61:513-29.

39. Carstensen T, Ødegaard NB, Bonsaksen T. Approaches to studying: Associations with learning conceptions and preferences for teaching. Cogent Educ. 2018;5.

DOI:10.1080/2331186x.2018.1480909

40. Severiens S, Dam G. A multilevel meta-analysis of gender differences in learning orientations. Brit J Educ Psychol. 1998;68:595-608. 
41. Berberoglu G, Hei LM. A comparison of university students' approaches to learning across Taiwan and Turkey. Int J Test. 2003;3:173-87.

42. Mattick K, Dennis I, Bligh J. Approaches to learning and studying in medical students: Validation of a revised inventory and its relation to student characteristics and performance. Med Educ. 2004;38:535-43.

43. Cantwell RH, Grayson R. Individual differences among enabling students: A comparison across three enabling programmes. J Furth High Educ. 2002;26:293-306.

44. Tetik C, Gurpinar E, Bati H. Students' learning approaches at medical schools applying different curricula in Turkey. Kuwait Med J. 2009;41:311-6.

45. Chamorro-Premuzik T, Furnham A. Mainly openness: The relationship between big five personality traits and learning approaches. Learn Individ Differ. 2009;19:524-9.

46. Diseth A. Students' evaluation of teaching, approaches to learning, and academic achievement. Scand J Educ Res. 2007;51:185-204.

47. Chonkar SP, Ha TC, Chu SSH, Ng AX, Lim MLS, Ee TX, et al. The predominant learning approaches of medical students. BMC Med Educ. 2018;18. DOI:10.1186/s12909018-1122-5

48. Zeegers P. Student learning in higher education: A path analysis of academic achievement in science. High Educ Res Dev. 2004;23:35-56.

49. Duff A, Boyle E, Dunleavy K, Ferguson J. The relationship between personality, approach to learning and academic performance. Pers Individ Differ. 2004;36:1907-20.

50. Crepeau EB, Cohn ES, Schell BAB, editors. Willard \& Spackman's occupational therapy. 10th ed. Philadelphia (PA): Lippincott, Williams \& Wilkins; 2003.

51. Parham D. Toward professionalism: The reflective therapist. Am J Occup Ther. 1987;41:555-61.

52. Crepeau EB, Schell BAB. Theory and practice in occupational therapy. In: Crepeau EB, Cohn ES, Schell BAB, editors. Willard \& Spackman's occupational therapy. 10th ed. Philadelphia (PA): Lippincott, Williams \& Wilkins; 2003. p. 203-7.

53. Diseth $\AA$. Validation of Norwegian version of the Approaches and Study Skills Inventory for Students (ASSIST): Application of structural equation modelling. Scand J Educ Res. 2001;45:381-94.

54. Byrne M, Flood B, Willis P. Validation of the Approaches and Study Skills Inventory for Students (ASSIST) using accounting students in USA and Ireland: A research note. Account Educ. 2004;13:449-59.

55. Entwistle N, Tait H, McCune V. Patterns of response to an approaches to studying inventory across contrasting groups and contexts. Eur J Psychol Educ. 2000;15:33-48. 
56. Reid WA, Duvall E, Evans P. Can we influence medical students' approaches to learning? Med Teach. 2005;27:401-7.

57. Ballantine JA, Duff A, Larres PM. Accounting and business students' approaches to learning: A longitudinal study. J Account Educ. 2008;26:188-201.

58. Brodersen LD. Approaches to studying and study tactics of baccalaureate nursing students (Doctoral thesis). Cedar Falls (IA): University of Northern Iowa; 2007.

59. Brown SA, Wakeling L, Naiker M, White S. Approaches to study in undergraduate nursing students in regional Victoria, Australia. Int J Nurs Educ Scholarship. 2014;11:155-64.

60. Bonsaksen T, Småstuen MC, Thørrisen MM, Fong K, Lim HB, Brown T. Factor analysis of the Approaches and Study Skills Inventory for Students in a cross-cultural occupational therapy undergraduate student sample. Austral Occup Ther J. 2019;66:33-43.

61. IBM Corporation. SPSS for Windows (version 26). Armonk (NY): IBM Corporation; 2019.

62. Stevens J. Applied multivariate statistics for the social sciences. 3rd ed. Mahwah (NJ): Lawrence Erlbaum; 1996.

63. Tabachnick BG, Fidell LS. Using multivariate statistics. 6th ed. Boston (MA): Pearson Education; 2013.

64. Richardson JTE, King E. Gender differences in the experience of higher education: quantitative and qualitative approaches. Educ Psychol. 1991;11:363-82.

65. Hayes K, Richardson JE. Gender, subject and context as determinants of approaches to studying in higher education. Stud High Educ. 1995;20:215-21.

66. McCrae RR, Costa PT, Ostendorf F, Angleitner A, Hrebickova M, Avia MD, et al. Nature over nurture: Temperament, personality, and life span development. J Pers Soc Psychol. 2000;78:173-86.

67. Costa PT, Terracciano A, McCrae RR. Gender differences in personality traits across cultures: Robust and surprising findings. J Pers Soc Psychol. 2001;81:322-31.

68. Sadler-Smith E. Approaches to studying: age, gender and academic performance. Educ Stud. 1996;22:367-79.

69. Richardson JTE. Mature students in higher education: I. A literature survey on approaches to studying. Stud High Educ. 1994;19:309-25.

70. Brown T, Fong KNK, Bonsaksen T, Lan TH, Murdolo Y, Gonzalez PC, et al. Approaches to learning among occupational therapy undergraduate students: A cross-cultural study. Scand J Occup Ther. 2017;24:299-310.

71. Bonsaksen T, Brown T, Lim HB, Fong K, Småstuen MC. Associations between occupational therapy students' approaches to studying and their academic grade results: A 
1 cross-sectional and cross-cultural study. J Occup Ther Educ. 2020;4.

2 DOI:10.26681/jote.2020.040105

3

4

5

6

7

8

9

10

11

12

13

14

15

16

17

18

19

20

21

22 
Table 1

National sample: Student characteristics and scores on the approach to study scales according to dominant study approach $(n=180)$

Dominant study approach

\begin{tabular}{|c|c|c|c|c|}
\hline Student characteristics & Deep & Strategic & Surface & $p^{\mathrm{b}}$ \\
\hline All students & $65(36.1)$ & $91(50.6)$ & $24(13.3)$ & \\
\hline Age group (n [\%]) & & & & 0.58 \\
\hline$\leq 19$ years & $2(12.5)$ & $12(75.0)$ & $2(12.5)$ & \\
\hline 20-24 years & $48(37.2)$ & $64(49.6)$ & $17(13.2)$ & \\
\hline 25-29 years & $11(47.8)$ & $8(34.8)$ & $4(17.4)$ & \\
\hline 30-35 years & $2(33.3)$ & $3(50.0)$ & $1(16.7)$ & \\
\hline 36-39 years & $0(0.0)$ & $1(100.0)$ & $0(0.0)$ & \\
\hline$\geq 40$ years & $2(40.0)$ & $3(60.0)$ & $0(0.0)$ & \\
\hline Gender (n [\%]) & & & & $<0.01$ \\
\hline Male & $22(61.1)$ & $11(30.6)$ & $3(8.3)$ & \\
\hline Female & $43(29.9)$ & $80(55.6)$ & $21(14.6)$ & \\
\hline Prior higher education (n [\%]) & & & & 0.31 \\
\hline Yes & $33(42.3)$ & $36(46.2)$ & $9(11.5)$ & \\
\hline No & $32(31.4)$ & $55(53.9)$ & $15(14.7)$ & \\
\hline Educational priority (n [\%]) & & & & 0.06 \\
\hline OT was highest priority & $40(35.7)$ & $62(55.4)$ & $10(8.9)$ & \\
\hline OT was not higher priority & $25(36.8)$ & $29(42.6)$ & $14(20.6)$ & \\
\hline Weekly hrs. spent on indep. stud. (M $[S D])$ & $8.7(6.6)$ & $10.0(7.2)$ & $8.6(7.6)$ & 0.50 \\
\hline \multicolumn{5}{|l|}{ Study approach scale scores $(M[S D])^{\mathrm{a}}$} \\
\hline Deep approach & $3.9(0.5)$ & $3.4(0.5)$ & $3.1(0.4)$ & $<0.001$ \\
\hline Strategic approach & $3.4(0.4)$ & $3.9(0.4)$ & $3.1(0.9)$ & $<0.001$ \\
\hline Surface approach & $2.9(0.4)$ & $2.8(0.6)$ & $3.7(0.4)$ & $<0.001$ \\
\hline
\end{tabular}

Note. $\mathrm{n}=$ sample size/number of observations; $M=$ mean; $S D=$ standard deviation; $\mathrm{OT}=$ occupational

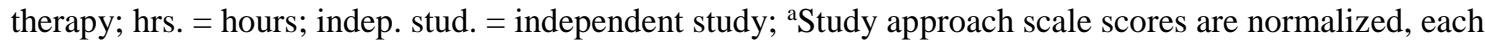
ranging 1-5; bStatistical tests are chi-square (categorical variables) and one-way ANOVA (continuous variables) 
Table 2

National sample: Associations between student characteristics and dominant approach to study, using surface approach as the reference category $(n=180)$

\begin{tabular}{|c|c|c|c|}
\hline Characteristics & OR & $95 \%$ CI for OR & $p$ \\
\hline \multicolumn{4}{|l|}{ Deep approach } \\
\hline Age group (lower age is ref.) & 1.06 & $0.60-1.87$ & 0.86 \\
\hline Male & 3.23 & $0.83-12.51$ & 0.09 \\
\hline Female & \multicolumn{3}{|c|}{ reference category } \\
\hline Prior higher education & 1.35 & $0.49-3.72$ & 0.57 \\
\hline No prior higher education & \multicolumn{3}{|c|}{ reference category } \\
\hline OT was highest priority & 2.17 & $0.81-5.79$ & 0.12 \\
\hline OT was not highest priority & \multicolumn{3}{|c|}{ reference category } \\
\hline Hrs. spent on indep. stud. (fewer is ref.) & 0.99 & $0.92-1.08$ & 0.86 \\
\hline \multicolumn{4}{|l|}{ Strategic approach } \\
\hline Age group (lower age is ref.) & 0.99 & $0.56-1.73$ & 0.96 \\
\hline Male & 0.91 & $0.22-3.71$ & 0.89 \\
\hline Female & \multicolumn{3}{|c|}{ reference category } \\
\hline Prior higher education & 1.05 & $0.39-2.81$ & 0.92 \\
\hline No prior higher education & \multicolumn{3}{|c|}{ reference category } \\
\hline OT was highest priority & $2.89 *$ & $1.13-7.39$ & $<0.05$ \\
\hline OT was not highest priority & \multicolumn{3}{|c|}{ reference category } \\
\hline Hrs. spent on indep. stud. (fewer is ref.) & 1.02 & $0.94-1.10$ & 0.66 \\
\hline Model $\chi^{2}$ & 19.3 & & $<0.05$ \\
\hline Pseudo $R^{2}$ (Cox and Snell [Nagelkerke]) & $0.10(0.12)$ & & \\
\hline
\end{tabular}

Note. Results from multinomial regression analyses; $\mathrm{n}=$ sample size/number of observations; ref. $=$ reference category; hrs. = hours; indep. stud. = independent study; OR = odds ratio; $\mathrm{CI}=$ confidence interval; OT = occupational therapy; ${ }^{*} p<.05$ 
Table 3

International sample: Student characteristics and scores on the approach to study scales according to dominant study approach $(n=665)$

Dominant study approach

\begin{tabular}{lcccc}
\cline { 2 - 3 } Student characteristics & Deep & Strategic & Surface & $p^{\mathrm{b}}$ \\
\hline All students & $229(34.4)$ & $350(52.6)$ & $86(12.9)$ & \\
Age group (n [\%]) & & & & 0.68 \\
$\leq 19$ years & $68(35.4)$ & $99(51.6)$ & $25(13.0)$ & \\
20-24 years & $126(32.9)$ & $201(52.5)$ & $56(14.6)$ & \\
25-29 years & $20(38.5)$ & $30(57.7)$ & $2(3.8)$ & \\
30-35 years & $8(44.4)$ & $9(50.0)$ & $1(5.6)$ & \\
36-39 years & $4(30.8)$ & $7(53.8)$ & $2(15.4)$ & \\
$\geq 40$ years & $3(42.9)$ & $4(57.1)$ & $0(0.0)$ & \\
Gender (n [\%]) & & & & $<0.05$ \\
Male & $43(46.2)$ & $40(43.0)$ & $10(10.8)$ & \\
Female & $186(32.5)$ & $310(54.2)$ & $76(13.3)$ & \\
Prior higher education (n [\%]) & & & & 0.22 \\
Yes & $91(37.0)$ & $130(52.8)$ & $25(10.2)$ & \\
No & $138(32.9)$ & $220(52.5)$ & $61(14.6)$ & \\
Weekly hrs. spent on indep. stud. $(M[S D])$ & $12.6(7.7)$ & $13.8(9.0)$ & $10.0(6.2)$ & $<0.01$ \\
Study approach scale scores $(M[S D])^{\mathrm{a}}$ & & & & $<0.001$ \\
Deep approach & $3.9(0.3)$ & $3.4(0.4)$ & $3.0(0.5)$ & $<0.001$ \\
Strategic approach & $3.4(0.4)$ & $3.9(0.4)$ & $3.1(0.5)$ & $<0.001$ \\
Surface approach & $3.0(0.5)$ & $3.0(0.4)$ & $3.7(0.3)$ & $<0.001$
\end{tabular}

Note. $\mathrm{n}=$ sample size/number of observations; $M=$ mean; $S D=$ standard deviation; hrs. = hours; indep. stud.

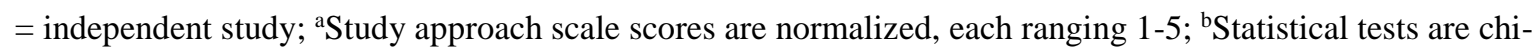
square (categorical variables) and one-way ANOVA (continuous variables) 3 4 5 
Table 4

International sample: Associations between student characteristics and dominant approach to study, using surface approach as the reference category $(n=665)$

\begin{tabular}{lccc}
\hline Characteristics & OR & $95 \%$ CI for OR & $p$ \\
\hline Deep approach & 1.18 & $0.84-1.66$ & 0.34 \\
Age group (lower age is ref.) & 2.11 & $0.99-4.49$ & 0.05 \\
Male & & reference category & \\
Female & 1.49 & $0.83-2.65$ & 0.18 \\
Prior higher education & & reference category & \\
No prior higher education & $1.07 * *$ & $1.03-1.11$ & $<0.01$ \\
Hrs. spent on indep. stud. (fewer is ref.) & & & 0.25 \\
\hline Strategic approach & 1.21 & $0.88-1.68$ & 0.63 \\
Age group (lower age is ref.) & 1.20 & $0.57-2.56$ & 0.37 \\
Male & & reference category & \\
Female & 1.29 & $0.74-2.26$ & $<0.001$ \\
Prior higher education & & reference category & \\
No prior higher education & $1.08 * * *$ & $1.04-1.13$ & \\
Hrs. spent on indep. stud. (fewer is ref.) & 30.0 & & \\
\hline Model $\chi^{2}$ & $0.04(0.05)$ & & \\
Pseudo $R^{2}$ (Cox and Snell [Nagelkerke]) & & & \\
\hline Note. Resuts fom minom & & \\
\hline
\end{tabular}

Note. Results from multinomial regression analyses; $\mathrm{n}=$ sample size/number of observations; ref. $=$ reference category; hrs. $=$ hours; indep. stud. $=$ independent study; $\mathrm{OR}=$ odds ratio; $\mathrm{CI}=$ confidence interval; $* * p<.01$; $* * * p<.001$ 